\title{
Classroom Management Difficulties in Science and Technology Courses*
}

\author{
Zeynep Nalan YILMAZ \\ Hakkari University, Hakkari, Turkey \\ Ozge AYDIN SENGUL \\ Dumlupınar University, Kutahya, Turkey
}

\begin{abstract}
A large part of learning and teaching activities take place in the classroom. For that reason, classroom management is seen as the most basic step of educational administration. Behaviors from curriculum programs are given to the students with effective classroom management. Classroom management is more difficult in science and technology courses in which students are more active and learning by doing than verbal courses. Starting from the purpose of the study, determinig classroom management difficulties of science and techology courses' teachers. For the purpose of the study, answers was sought to the following research questions: What are the ideas of sceince and technology teachers regarding classroom management difficulties? How are science and technology teachers' classroom management difficulties reflected to their practices? The study was done by using "descriptive situation analysis" and data were obtained by the "interviews" and "observation." Interview protocol and observation protocol were developed in or to use this research. The individual interview protocol consists of semi-structured, open-ended questions design to obtain response that pertains to the research questions. Observation protocol consists of questions in order to guide observation. During the interviews, questions about five different dimensions of classroom management are directed to teachers and their difficulties in these dimensions are determined. The observation process is going to be one month in the class and during that month determined how these difficulties are reflected to their practices. The participants of the study are four science and technology teachers who are working at secondary school in Hakkari, Turkey. The data were collected in 2013-2014 academic year. A content analysis was used to transcribe data from each interview and observation into major categories. By identifying major categories sub-categories created within the major categories for further interpretations. Results were given about five different dimensions of classroom management. In regard to the physical arrangement the findings obtained from the interviews showed that teachers are not pleased with the number of students in the classrooms and physical constraints in the schools. Concerning the management of the learning and teaching activities, the participants most frequently stated that planning is the key term. Regarding the management of relations, it was found that teachers have communicative relations with parents, but such relations are attempted only by teachers. Time management by the participants was also affected by the level of the students. Concerning the management of behaviors, it was found that the most frequent undesired student behaviors are "talking without permission," "walking around the classroom without permission," and "conversing with friends during the course." The most frequent strategy to
\end{abstract}

* This study was presented as an oral presentation on 9-13 July 2014 at Thistle Brighton, The European Conference on Education that was organized in United Kingdom.

Zeynep Nalan YILMAZ, asstant professor, Faculty of Education, Hakkari University.

Ozge AYDIN SENGUL, Dr., asstant professor, Faculty of Education, Dumlupınar University. 
reduce the undesired student behaviors employed by the participants were found to be "making eye contact,"

"verbal warnings," "personally talking to students," and "informing the parents about the undesired behaviors."

Keywords: science and technology courses, classroom management, science and technology teachers

\section{Introduction}

The majority of the educational and teaching activities take place in the classroom settings. Therefore, the first and basic step in the educational management is the classroom management. It can be defined as the provision and continuation of an optimum learning environment through the realization of educational plans and programs, activities, educational methods, and the interaction between teacher and students (Saritas, 2000). Furthermore, classroom management is developed with students via behavioral codes and standards concerning a safe learning environment. In addition, it includes the identification of teaching methods and the ways to make active participants of the teaching process (Celep, 2004). Classroom management is the authorian dominance of teachers in classrooms, but the provision of a classroom setting which makes it possible for students to learn (Tertemiz, 2007).

Teachers are responsible for making in-class behaviors proper for the goals of the course and for organizing learning experiences (Basar, 2009). Teachers are significant role models for students, particularly for basic education students. Acıkgoz (2007) argued that teachers should be models and guides for students in addition to their basic task of "facilitating the student learning."

Research mainly focuses on undesirable behaviors by students. Undesired student behaviors indicate a discipline problem in classrooms. In order to reduce discipline problems in classrooms, teachers should have necessary classroom management skills (Yilmaz \& Aydin, 2015). A good classroom management requires the following teacher skills: communicative skills, planning and organization skills, competency in explaining and demonstrating related points, and the skills related to motivation and strengthening the student learning (Gozutok, 2004). For teachers who try to provide an efficient teaching and learning process, one of the most significant skills is to manage the students and resources in the classroom in parallel to the aims (Demirtas, 2008).

There are many variables affecting classroom management as follows: classroom climate, interactional organization, better relations, student participation, and behavioral norms (Brophy, 1988; Harris, 1991; Chiang, 1991, as cited in Basar, 2009). The dimensions classroom management is physical arrangement, management of the teaching and learning activities, management of relations, time management, and management of behaviors. Physical arrangement includes those variables, such as the number of students, seating arrangement, temperature and lighting, noise and cleaning (Basar, 2009). The management of learning and teaching activities covers the followings: (1) Well planned courses to avoid the undesired student behaviors and to make them focus on the tasks; and (2) The use of the complementary measurement and evaluation techniques to maintain their interest in the course. The management of relations is the basis for the effective relationships between teachers and parents, between teacher and students, and among students and for the positive classroom environment. Time management refers to the use of class hour in a productive way which reflects the teachers' major professional responsibility and competency (Aydin, 2010). The management of behaviors requires that teachers should direct students to desired behaviors. However, the reasons for desired behaviors should clearly be communicated. On the other hand, desired behaviors should be age-appropriate and based on development 
levels of students. However, it should be noted that undesired behaviors may occur despite the steps taken. Through the use of classroom management skills in an effective way, these behaviors may be reduced.

Teachers' styles in regard to the classroom management may vary based on the subject matter. It is known that classroom management is much more difficult in the foreign language courses as well as in science courses due to nature of them. Because these courses are student-centered, which require active student participation. In a similar vein, the 2005 program of the science and technology course in Turkey left the teacher-centered approach. Instead, it requires students to be curious and active in the process, and challenge the subject matter and therefore, it has an approach of student-centered teaching and learning (Kiraz, 2007). Therefore, due to continuous student movement in the classroom may make it difficult for teachers to manage the classroom. On the other hand, teachers have different tasks to do in the classroom. Therefore, this study deal with the problems experienced by science and technology teachers concerning classroom management.

The aim of this study is to determine classroom management difficulties experienced by the science and technology teachers. The study tries to answer the following research questions are:

1. What are the views of science and technology teachers regarding classroom management difficulties?

2. How are science and technology teachers' classroom management difficulties reflected to teachers' practices?

\section{Method}

The study was done by using "descriptive situation analysis" and the data were obtained by the "interviews" and "observations." The interview protocol and observation protocol were developed by the authors. The individual interview protocol consists of five semi-structured, open-ended questions which were designed to obtain data about the research questions. The observation protocol consists of eight questions which guide observation process.

During the interviews, the questions about five different dimensions of classroom management were asked to the teachers and their difficulties in these dimensions were determined. The observation process lasted for one month in the classroom and researchers observed how these difficulties were reflected in the teachers' practices during this period. Each interview was recorded. Audio recordings were listened twice before transcription. Following the repeated listening of audio recordings, the interview data were transcribed.

\section{Data Analysis}

The process of the data analysis involved several iterations of reading and coding interview transcripts, and observation data in order to identify patterns. Patterns emerging from one data source were checked and triangulated with other data sources for the same case until similar patterns keep recurring. The triangulation of data provided rigor the study. A content analysis was used to analyze data from each interview and observation to develop major categories. By identifying major categories, sub-categories created within the major categories for further interpretations.

\section{Participants}

The participants of the study were five science and technology teachers who worked at a secondary school in Hakkari, Turkey, during the 2013-2014 academic years. Four participants were males and one female. In regard to teaching experience, one participant had lower than one year experience, two has a teaching experience of two-four years, and the remaining two had an teaching experience of five-10 years. Four teachers 
were graduates of science teaching department and one of biology teaching department, but all of them were working as a science and technology teacher. All of the participants took the course of classroom management in their teacher training program.

\section{Findings}

The themes and codes developed for the interviews and observations are given in Table 1 below:

Table 1

List of Themes and Codes

\begin{tabular}{|l|l|}
\hline Themes & Codes \\
\hline Physical arrangement & $\begin{array}{l}\text { The number of students } \\
\text { Seating arrangement } \\
\text { Arrangement of teacher's table } \\
\text { Temperature } \\
\text { Lighting } \\
\text { Cleanliness }\end{array}$ \\
\hline Management of learning-teaching activities in science courses & $\begin{array}{l}\text { Preliminary activities } \\
\text { Planning } \\
\text { Assessment }\end{array}$ \\
\hline Management of relations & $\begin{array}{l}\text { Communication between teacher and students } \\
\text { Communication between teacher and parents }\end{array}$ \\
\hline Time management & $\begin{array}{l}\text { Level of class } \\
\text { Student motivation } \\
\text { Level of students }\end{array}$ \\
\hline Management of behaviors & $\begin{array}{l}\text { Desired behaviors } \\
\text { Undesired behaviors } \\
\text { Reactions towards behaviors }\end{array}$ \\
\hline
\end{tabular}

Based on the interviews and observations and the review of literature, five themes about classroom management were developed as follows: physical arrangement, management of learning-teaching activities in science courses, management of relations, time management, and management of behaviors. The following section includes first the views of the participants about the classroom management and examples from the observations.

The participants commented on the physical arrangement of classrooms in terms of the number of students, seating arrangement, arrangement of teacher's table, temperature, lighting, and cleanliness. Sample views are given below:

If there were other opportunities, the seats of the students would be arranged differently, but we used a classical seating arrangement which makes it possible for students to see the board. In other words, we use it due to the high number students and due to disadvantageous lighting and the position of the board.

The number of the students is higher in the classroom. For me, there should be 11 or 12 students in the science classes. The $U$ shape of seating arrangement would be advantageous for communication, but it is not possible due to the number of students. The position of teacher table should be in a way to teacher could dominate the class and could develop eye contact with each student. The higher number of students also inhibits the experiments in the classroom. We could not let students to do the experiments, too.

There are classrooms in the basement floor in our school. These classrooms are dark and air-conditioning is poor. When we try to make the experiments there the atmosphere of the classroom becomes very bad and students are subject to harmful gases. Therefore, out opportunity to make experiments is very limited.

There are classrooms without projection. It is very significant deficiency in that using simulations for the experiments is very advantageous. 
The number of the students is not appropriate for making individual experiments. Group experiments are not also available, since the number of members is again higher. Therefore, it is very difficult to check their work. For the science courses, we need less student number and good lighting.

For science courses, there should be some special arrangements. For instance, laboratories can be used for the class, because students need visual materials and we should do experiments. I think that much more productive courses can be offered in laboratories and that seating arrangements and the number of students should be at the optimum level for such activities.

The management of learning-teaching activities in science courses was evaluated by the participants in terms of preliminary activities, planning, and assessment. Sample views are given as follows:

I teach the 5th and 9th graders. The science course of the 5th graders is totally directed to activities and to develop materials by the students. Activities are designed to make the students like and adopt the course. Therefore, I try to realize these activities in the textbook. Children like to develop something on their own and have interest in these activities. The most advantageous side of the science topics is that these topics are closely related to daily-life topics and activities. They may bring canned food made by their mothers to the classroom. In addition, I try to use visual materials as much as possible.

We plan course time based on the units. Therefore, we take into consideration units in planning the time. We plan what we should offer about this topic in one class hour and which units should emphasized. We try to make the plans to complete the related topic in a class hour.

We plan the next experiment in advance, since it takes longer time to organize it. We have difficulty in planning the units due to time constraints.

The participants commented on the management of relations in terms of the relationship between teachers and parents and between teacher and students. Their views in this regard are given below:

In our school, the interactions between parents, students and teachers are well. Because teachers visit homes each semester in a year. I have phone numbers of all parents and call them whenever it is necessary. I meet with the parents occasionally in addition to teacher-parents meetings in the schools. I try to make the parents to become familiar with one another, since their closeness has positive effects on solving the problems in the classroom.

We have sincere and good relations with our students.

Students do not have necessary levels of interest over the subject matter. I think that because of too many children in the family, they can not deal with children and even if you laugh, so it is enough for them.

I try to communicate with my students, but I have some problems with some students in this regard. There are students who have problems in communication due to their familial problems.

I do not think that parents have no interest in their children's learning and they are not in cooperation with us. It reflects on students and they become uninterested in the course.

Science and technology teachers commented on class level, student motivation, and level of students in terms of time management. Sample views are given below:

For the 5th graders, time is enough and we can do and repeat activities. We even have time for individual activities. However, for the 6th graders, there are time constraints and units are very extensive and some units have 18 outcomes. Therefore, I could not able to catch up with such constraints.

Time management is based on whether or not we can motivate students for the course. Due to the fact that ability levels of students are different in the class, time management is negatively affected.

I give the lesson, but science is a very detailed subject, so that children ask numerous questions and the class hour is not enough to both answer these questions and lecture all the topics. I could only deal with the half of the topics, since I want to answer their questions. Therefore, I could not use the class hour effectively.

The participants commented on the classroom management in terms of desired and undesired behaviors and reactions related to the behaviors. The examples are as follows: 
When any undesired behaviour occurs, I do not want to hurt the related student in the classroom. Instead, I try to express my feeling through my look.

The most frequent undesired behaviour I come across is the talking of students without asking for permission. They lift their finger and begin to talk. However, lifting a finger does not mean that he has the right to talk in the classroom.

In general, we give them chocolate as a reinforce for their desired behaviors.

The method used in the activities is also very important. When students come to the board they should be rewarded through verbal praise or chocolate.

Students say "teacher" while lifting their fingers. So, it is very tiring to respond them.

When any undesired behaviour occurs, I first verbally warn the student. If he repeats such behaviors I meet with his parents or talk to him personally in a setting other than classroom.

Some students may unrespectfully behave one another. It is probable that such situations occur due to the different familial patterns. I think that their concepts about love and respect are not totally developed.

In the classroom, it is commonly seen that students chew gum, talking without permission, and walking around the classroom without permission.

I mostly come across such undesired behaviors as not listening to the lecture and talking to friends during the lecture, but I have not observed any unrespectful student behaviour. In addition, students want to make dangerous experiments.

Students do not follow seating arrangement of the class. Some students go to their friends' desks during the lecture. When I do not warn him, it becomes a habit of him.

The following data and examples are from the observations made in the classrooms about the themes of classroom management.

\section{Theme of the Physical Arrangement of Classroom}

The classes are organized in a classical seating arrangement. Temperature and cleaning are appropriate and the number of students in a classroom varies between 21 and 30 .

Boards in the classrooms are not systematically organized in that they are not used for each course subject. On the walls, there are some papers.

\section{Theme of the Management of the Learning and Teaching Activities in Science Courses}

A student is reading a text from the textbook and the others are listening to him.

At the beginning of the lesson, teacher asks questions about the experiment carried out in the last course. Then, he draws a figure about this experiment and briefly gives information about the experiment. He asks the students to give related examples to make them to participate in the lesson.

Teacher says that he will control the homework assignments in the next lesson. He controls all assignments himself.

Teacher finishes the lesson through question-answer technique. He writes down short notes on the board, but students do not take notes.

\section{Theme of the Management of Relations}

Teacher has a humoristic communication with the students.

He gives the lesson using vernacular language.

He has positive communicative relations with the students. When a student cannot answer his question, he asks other questions to help him finding the correct the answer.

He addresses the students using their names.

\section{Theme of Time Management}

Teacher looks like well planned the class hour, during the last 10 minutes, he briefly roundup the unit. 
Teacher calls the roll while students take notes from the board. During the last five minutes of the lesson, he roundups the unit.

He gives time the students to solve the problems, and says, "I will take your questions later" to other students asking additional questions.

He tries to obey the class hour and finishes the lesson as he planned.

\section{Theme of Behaviour Management}

Teacher warns the student who says "teacher," while lifting his finger and tells him "Just lift your finger."

Teacher says, "Very well" when students give correct answers. He also provides the students with the opportunity think about the question.

Teacher says, "Did you want right to talk?" to the student who talks without permission.

There are no many students who negatively behaved. However, there are students who do not participate in the lesson.

Teacher says, "I will talk to your parents about it." to a student who hits his friend while entering into the classroom.

Teacher makes eye contact with the students who do not listen to the lesson and follow the class rules.

Teacher says, "Well done" to a student who correctly answers the question and gives a candy to him. $\mathrm{He}$ uses it as a reinforcer to increase the frequency of the desired behaviors.

Teacher verbally warns the students who do not listen to the lesson and asks them several questions.

Teacher verbally warns a student who stands up and go to near to the wastebasket without taking permission.

\section{Discussion, Conclusion, and Suggestions}

The findings of the study are discussed below in relation to five major dimensions of the classroom management:

1. In regard to the physical arrangement, the findings obtained from the interviews showed that teachers are not pleased with the number of students in the classrooms and physical constraints in the schools, such as lack of an independent science laboratory, lack of projection equipment in the classroom, and poor lighting in the classrooms negatively affect the activities related to the classroom management. Observations of the classrooms also showed that using classical seating arrangements in the classrooms is a result of the crowded classrooms. In addition, the observation data also confirm the views of the participants expressed in the interviews. There are many researches dealing with the correlations between the number of students in a classroom and the student achievement. For instance, Finn and Archilles (1990) found that there is a positive correlation between less number of students and the student achievement (as cited in Basar, 2009). Yaman (2010) argued that crowded classes lead to serious problems in the provision of the optimum teaching and learning environment, classroom management, personal hygiene of the students resulting health-related problems.

2. Concerning the management of the learning and teaching activities, the participants most frequently stated that planning is the key term. When planning is well done, classroom activities are implemented in parallel to the goals. This fact was also seen in the observations made in the study. Adiguzel (2009) studied the difficulty levels of the classroom teachers in organizing the learning activities and in implementing such activities. It was found that classroom teachers do not perceive themselves totally competent in planning the 
teaching activities, developing learning materials, making the teaching diversified, and arranging the learning environment.

3. Regarding the management of relations, it was found that teachers have communicative relations with parents, but such relations are attempted only by teachers. The participants described their relations with the students as sincere and natural. In the observations, sincere relations between teachers and students were observed and it was seen that they addressed the students using their names. Balabanoglu and Korkut (2010) found that classroom teachers are very good in the arrangement of the relations between teacher and students.

4. Concerning time management, it was found that time management by the participants varies based on the grade levels. In addition, time management by the participants was also affected by the level of the students. It was observed that the participants used the last minutes of the courses for briefing the topic. Adiguzel (2009) found that teachers experience difficulty in effective planning of the courses and in guiding the students to effectively use their in- and out- class time.

5. Concerning the management of behaviors, it was found that the most frequent undesired student behaviors are "talking without permission," "walking around the classroom without permission," and "conversing with friends during the lesson." The most frequent strategy to reduce the undesired student behaviors employed by the participants were found to be "making eye contact," "verbal warnings," "personally talking to students," and "informing the parents about the undesired behaviors." The observations also confirm these statements. Balay and Saglam (2008), based on the teacher views, identified examples of the most frequently undesired behaviors occurred in the classrooms as follows: "interrupting others' talking," "talking without taking permission," "being late for the course," "walking around the classroom without permission," and "improper sitting in the seat." The attitudes of teachers towards undesired behaviors are very significant. Sezgin and Duran (2010) found that the following strategies are commonly used to modify undesired behaviors of students: "going near to the student" and "asking questions to make the students participants of the lesson." Teachers were also found not to employ the strategies of implementing discipline norms or shouting at the students. Sartas (2006) found that student teachers mostly employ the following strategies to eliminate the undesired behaviors: avoiding talks among students, and trying to make them to participate in the lesson through giving responsibilities.

\section{References}

Acıkgoz Un, K. (2007). Etkili oğrenme ve oğretme. İzmir: Biliş Özel Eğitim Danışmanlık Yayınları.

Adiguzel, A. (2009). The level of to be forced during the activity of learning in arrangement and implementing effort of class teachers. Yuzuncu Yil University Journal of the Faculty of Education, 6(2), 89-110.

Aydin, A. (2010). Sinıf yönetimi. Ankara: PegamA Yayınları.

Balaban, E., \& Korkut K. (2010). The correlation between level of classroom teachers' self-efficacy beliefs and classroom management ability perceptions. Inonu University Journal of the Faculty of Education, 11(1),1-19.

Balay, R. ve Saglam, M. (2008). The opinions of teachers concerning the negative behaviors in class. Yuzuncu Yil University Journal of the Faculty of Education, 5(2), 1-24.

Basar, H. (2009). Sinıf yönetimi. Ankara: Anı Yayınc1lık.

Celep, C. (2004). Sinıf yönetimi ve disiplini. Ankara: Anı Yayıncılık.

Demirtas, H. (2008). Sınıf yönetiminin temelleri. In H. Kiran (Ed.), Etkili sınıf yönetimi. Ankara: Anı Yayıncılık.

Gozutok, F. D. (2004). Öğretmenliğimi geliştiriyorum. Ankara: Siyasal Kitabevi.

Kiraz, A. (2007). A role model of effective use of collaborative learning approach with other methods. VI. International Primary Teacher Educaton Symposium, Anadolu University, Eskisehir. 
Kiraz, A., \& Omag, K. (2013). The perceptions of students towards the classroom management techniques used by science and technology teachers. H. U. Journal of Education, 44, 198-211.

Korkut, K., \& Babaoglan, E. (2010). Classroom management ability of classroom teachers. Dumlupinar University Journal of Social Sciences, 2(26), 146-156.

Sarıtas, M. (2000). Sinıf yönetimi ve disiplinle ilgili kurallar geliştirme ve uygulama: Sinıf yönetiminde yeni yaklaşımlar. L. Kucukahmet (Ed.). Ankara: Nobel Yayınları.

Saritas, M. (2006). The strategies used in order to change and ameliorate the students' classroom behaviors that are considered undesirable in the evaluations of teacher trainees. Uludag University Journal of the Faculty of Education, 19(1), 167-187.

Sezgin F., \& Duran, E. (2010). Prevention and intervention strategies of primary school teachers for the misbehaviors of students. Gazi University Journal of the Gazi Educational Faculty, 30(1), 147-168.

Tertemiz, N. (2007). Sınıf yönetimi ve disiplin. In L. Kucukahmet (Ed.), Sinıf yönetimi. Ankara: Nobel Yayınları.

Yaman, E. (2010). The effects of the crowded classrooms: What are the students thinking? Kastamonu Education Journal, 18(2), 403-414.

Yilmaz, Z. N., \& Aydin, O. (2015). Investigation of primary school teachers' perceptions of classroom management skills with respect to some variables. Mersin University Journal of the Faculty of Education, 11(1), 148-164. 